\title{
Repeatedly Heated Vegetable Oils and Lipid Peroxidation
}

\author{
Kamsiah Jaarin and Yusof Kamisah \\ Additional information is available at the end of the chapter
}

http://dx.doi.org/10.5772/46076

\section{Introduction}

Deep frying is the most common and one of the oldest methods of food preparation worldwide. It involves heat and mass transfer. To reduce the expenses, the oils tend to be used repeatedly for frying. When heated repeatedly, changes in physical appearance of the oil will occur such as increased viscosity and darkening in colour [1], which may alter the fatty acid composition of the oil. Heating causes the oil to undergo a series of chemical reactions like oxidation, hydrolysis and polymerization [2]. During this process, many oxidative products such as hydroperoxide and aldehydes are produced, which can be absorbed into the fried food [3].

Palm and soy oil are the most commonly used vegetable oils in the household and industry in Malaysia for deep frying purposes. Both palm and soy oils are rich in tocopherols [4-5]. In addition to the tocopherols, palm oil also contains an abundant amount of tocotrienols. The latter form of vitamin $\mathrm{E}$ was consistently shown to possess better antioxidant activity than the former form [6]. The soy oil has bigger proportion of polyunsaturated fatty acid compared to the palm oil. Whereas in the palm oil, the major fatty acids present are the monounsaturated and saturated fatty acids [7].

A survey conducted in Kuala Lumpur recently had revealed that majority of the respondents admitted using repeatedly heated cooking oil [8]. The public level of awareness regarding such usage is influenced by the socioeconomic status. Respondents with higher income and education level had higher level of awareness [9]. Chronic consumption of repeatedly heated vegetable oils could be detrimental to health. It was shown to demonstrate genotoxic and preneoplastic change in the rat liver [10]. It also impaired fluid and glucose intestinal absorption in rats [11]. In rats given alcohol plus heated sunflower, an apparent liver damage as well as increased cholesterol level was observed [12]. Soriguer et al. [13] found an independent positive association between the risk of hypertension and 
intake of heated cooking oil. These accumulating data suggest chronic intake of heated cooking oils increases the risk of cancer and cardiovascular diseases.

The incidence of cardiovascular disease is higher in men compared to women of similar age [14]. However, after menopause, the risk increases in women due to deficiency of estrogen level. The estrogen was shown to be cardioprotective in ovariectomized female rats [15]. It also possesses antioxidant activity which can lower the risk of lipid peroxidation [16]. Ovariectomized female rats have been used widely as a postmenopausal model [17-18].

In this study, we used two models, normal male rats and ovariectomized female rats to compare the effects of prolonged consumption of repeatedly heated palm oil and soy oil on in vivo plasma lipid peroxidation content. The oxidative stability of these repeatedly heated palm oil and soy oil were also compared.

\section{Materials and methods}

\subsection{Animals, materials and chemicals}

Male and female Sprague Dawley rats (180-200 gram) were obtained from the Laboratory Animal Resource Unit of Universiti Kebangsaan Malaysia. They were kept in polyethylene cages in a well ventilated room at room temperature. Food and water were provided ad libitum. Palm oil (Lam Soon Edible Oil, Malaysia) and soy oil (Yee Lee Edible Oil, Malaysia) were used in this study. Sweet potatoes were purchased from the same source at a local market. All chemicals and enzymes were obtained from Sigma-Aldrich (St. Louis, MO, USA), unless otherwise stated.

Ethical approval regarding the experimental procedure and humane animal handling in the study was obtained from the Universiti Kebangsaan Malaysia Animal Ethical Commitee and Medical Research Ethics Committee.

\subsection{Frying procedure}

The oils were heated according to the method of Owu et al. [19]. A kilogram of sweet potato slices were fried in a stainless steel wok containing two and half litres of palm oil or soy oil for 10 minutes at $180^{\circ} \mathrm{C}$. Upon completion of the frying process, once heated oil was obtained. The process was repeated four times to obtain five times heated oil with a cooling interval of at least five hours. The food quantity was proportionately adjusted with the amount of vegetable oil left. No fresh oil was added between the frying processes to make up for the loss due to uptake by the frying materials. After being heated, small quantity of the oils was extracted for the peroxide value, fatty acid composition and vitamin E content measurements.

\subsection{Diet preparation}

Diets enriched with heated palm or soy oils were prepared by mixing $850 \mathrm{~g}$ grinded standard mouse pellet with $150 \mathrm{~g}$ heated oil. While to prepare high cholesterol (2\%) diets fortified with heated palm or soy oils, $150 \mathrm{~g}$ palm or soy oil were mixed with $20 \mathrm{~g}$ cholesterol 
(MP Biomedical Inc., Australia) with $830 \mathrm{~g}$ grinded standard mouse pellet. The pellets were then remolded and dried in an oven at $80^{\circ} \mathrm{C}$ overnight.

\subsection{Effects of heated oils in male rats}

After one week of acclimatization period, forty-two male Sprague Dawley rats were randomly divided into seven groups. The first group was given standard mouse pellet (control). The second, third and fourth groups were given fresh, once and five times heated palm oil diets, while the fifth, sixth and the last groups were given fresh, once and five times heated soy oil diets, respectively for four months. Blood was sampled before and at the end of treatment duration.

\subsection{Effects of heated oils in ovariectomized female rats fed high cholesterol diet}

Forty-two female Sprague Dawley rats were allowed to acclimatize for a week before the treatment was started and were ovariectomized ahead of the study. They were randomly divided into seven groups. Group 1 was fed 2\% cholesterol diet (control), while groups 2, 3 and 4 were respectively fed $2 \%$ cholesterol diet added with fresh, once and five times heated palm oil. Groups 5, 6 and 7 were respectively given $2 \%$ cholesterol diet added with fresh, once and five times heated soy oil. The treatment duration was four months, after which the rats were sacrificed and blood samples were taken. Blood sample was also taken prior to the treatment.

\subsection{Peroxide content measurement}

Measurement of peroxide values of the heated oils was done according to the American Oil Chemists' Society (AOCS) Official Methods Cd 8-53 [20]. Briefly, five grams of the oil sample were added with $30 \mathrm{ml}$ of acetic acid-chloroform (3:2) in a flask. The flask was then swirled before the addition of $0.5 \mathrm{ml}$ saturated potassium iodide. The solution was swirled again for a minute. An amount of $30 \mathrm{ml}$ distilled water and a few drops of starch solution $(10 \%)$ were added. The solution was titrated against $0.01 \mathrm{~N}$ sodium thiosulphate solution which was priorly standardised using potassium dichromate and potassium iodide, until blue colour disappeared. The peroxide value in the oils was calculated as the difference in the volume of sodium thiosulphate solution $(\mathrm{ml})$ used for samples and blank, divided by its normality. The values were expressed in miliequivalents of peroxide per kilogram of the sample.

\subsection{Fatty acid composition measurement}

Fatty acid composition in the fresh and heated oils was analysed using gas chromatography (GC-17A, Shimadzu, Japan), which consisted of a flame ionisation detector, a BPX 70 capillary column ( $30 \mathrm{~m} \times 0.25 \mathrm{~mm} \times 0.25 \mu \mathrm{m})$, programmable injector temperature, set at $250^{\circ} \mathrm{C}$ and detector temperature, set at $280^{\circ} \mathrm{C}$. The oil samples $(100 \mu \mathrm{l})$ were first 
transesterified to fatty acid methyl ester using $1 \mathrm{ml}$ of $1 \mathrm{M}$ sodium methoxide in $1 \mathrm{ml}$ hexane before injected into the gas chromatographic system. The injection volume was $1 \mu \mathrm{l}$. Nitrogen at a flow rate of $0.40 \mathrm{ml} / \mathrm{min}$ was used as carrier gas in the analysis. Identification of fatty acid methyl ester peaks was carried out by comparing their retention times with their authentic standards. The fatty acid composition was expressed as the percentage of the total fatty acids.

\subsection{Vitamin E content measurement}

The vitamin E content in the oil samples (20 $\mu$ l sample) was analysed using an analytical high performance liquid chromatography (HPLC) using a programmable fluorescence detector at excitation $295 \mathrm{~nm}$ and emission $330 \mathrm{~nm}$ (Hewlett Packard HP1100, USA). The chromatographic system consisted of an isocratic pump and the stationary phase was a 150 $\mathrm{mm}$ silica normal phase column (YMC 5U) with an internal diameter $6 \mathrm{~mm}$. The mobile phase was $0.5 \%$ isopropanol in hexane at a flow rate of $1 \mathrm{ml} / \mathrm{min}$. The oil samples were injected directly into the HPLC system without any processing, after being cooled from the heating process. The vitamin E standard was obtained from the Malaysian Palm Oil Board (Bangi, Malaysia). Vitamin E measurement in the oils was done for six samples $(n=6)$ for each of the three corresponding groups; fresh, once and five times heated. The vitamin $\mathrm{E}$ content in the oils was expressed as part per million (ppm). The estimated percentage of difference compared to the respective fresh oils was also calculated.

\subsection{Plasma lipid peroxidation measurement}

Lipid peroxidation content in the plasma measured as thiobarbituric acid reactive substance (TBARS) was determined following a method described by Ledwozyw et al. [21] with some modification. Briefly, $2.5 \mathrm{ml}$ trichloroacetic acid $(1.22 \mathrm{M}$ in $0.6 \mathrm{M} \mathrm{HCl})$ was used to acidify $0.5 \mathrm{ml}$ plasma and incubated at room temperature for 15 minutes. Next, $1.5 \mathrm{ml}$ of $0.67 \%$ thiobarbituric acid (in $0.05 \mathrm{M} \mathrm{NaOH}$ ) was added. The samples were then incubated at $100^{\circ} \mathrm{C}$ for 30 minutes. After being cooled, the lipid peroxide content was extracted by the addition of $4 \mathrm{ml}$ butanol using vigorous shaking. Later, the samples fluorescence unit was read at 515 $\mathrm{nm}$ (excitation wavelength) and $553 \mathrm{~nm}$ (emission wavelength) using a spectrofluorometer (Shimadzu RF500, Japan). 1,1,3,3-Tetraethoxypropane was used as the standard. The unit of the plasma lipid peroxidation was nmol malondialdehyde/mg protein. The results were shown as the difference percentage of post-treatment content compared to the pretreatment content.

The protein content in the plasma was carried out according to the method of Lowry et al. [22], using bovine serum albumin as the standard. A plasma sample $(0.5 \mathrm{ml})$ was added with $5 \mathrm{ml}$ mixture of sodium carbonate $(2 \%)$, sodium potassium tartrate $(2 \%)$ and copper sulphate $(1 \%)$ solution at a ratio of $100: 1: 1$, prior to incubation at room temperature for 15 minutes. Subsequently, $0.5 \mathrm{ml}$ Folin-Ciocalteau phenol reagent $(0.5 \mathrm{~N})$ was added and then was left to stand at room temperature for 35 minutes. The absorbance of the samples was read at $700 \mathrm{~nm}$ with a spectrophotometer (Shimadzu UV-160A, Japan). 


\subsection{Statistical analysis}

The results were expressed as the means \pm standard error of mean (SEM). Normality of the data was analysed using Kolmogorov-Smirnov test. For normally distributed data, they were then analysed using one-way analysis of variance (ANOVA) followed by Tukey's HSD post-hoc test. While for not normally distributed data, the differences among the groups were determined using Kruskal-Wallis $\mathrm{H}$ and Mann-Whitney $\mathrm{U}$ test. Values of $\mathrm{P}<0.05$ were considered statistically significant. All statistical analyses were performed using SPSS version 13.0 (SPSS Inc., Chicago, IL, USA).

\section{Results}

\subsection{Peroxide value in the oils}

The peroxide values measured in the oils are shown in Figure 1. The values in the once and five times heated palm and soy oils were significantly elevated compared to the fresh oil respectively. In five times heated oils, the values were also significantly higher than the once heated oils. Fresh and five times heated soy oils had bigger peroxide values compared to those of palm oils. According to the American Oil Chemists' Society (AOCS) [23], only five times heated soy oil had peroxide value exceeded the maximum allowable peroxide value for edible oils (> $10 \mathrm{meq} / \mathrm{kg}$ ).

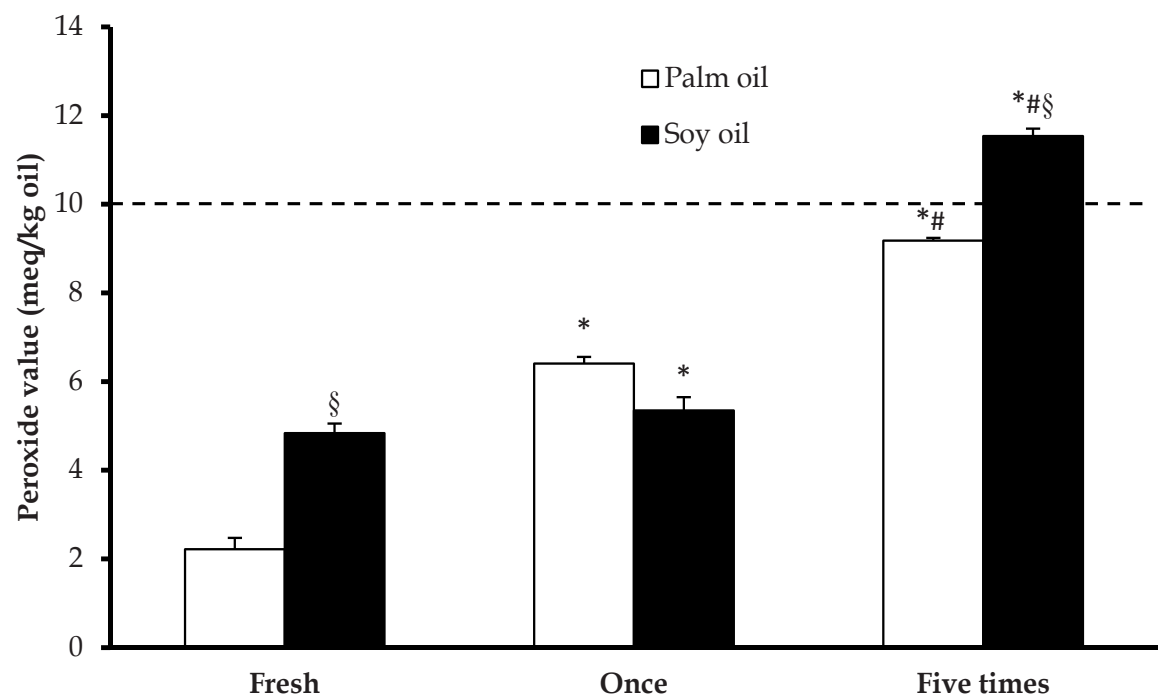

Figure 1. The peroxide values (meq $/ \mathrm{kg}$ ) in fresh and heated palm and soy oils. Bars represent mean \pm SEM $(\mathrm{n}=6)$. *Significantly different from the fresh oils respectively $(\mathrm{P}<0.05)$. \#Significantly different from the once heated oils respectively $(\mathrm{P}<0.05)$. §Significantly different from the palm oil groups respectively $(\mathrm{P}<0.05)$. Dashed horizontal line indicates maximum allowable peroxide value for edible oils according to the American Oil Chemists' Society (AOCS) [23]. 


\subsection{Fatty acid composition of the oils}

The fatty acid composition in both palm and soy oils is tabulated in Table 1. All the main components of fatty acid were present in the oils regardless of the frequency of heating. Once and five times heated palm oils had similar percentages of saturated, monounsaturated and polyunsaturated fatty acids composition compared to the fresh palm oil. In heated soy oil, generally the fatty acid composition was somewhat similar to the fresh oil. However, its polyunsaturated fatty acid percentage seemed to be lower than once heated and fresh oils. Overall, heating did not affect saturated and monounsaturated and polyunsaturated fatty acids components of palm oil. However, the repeated heating reduced the percentage of polyunsaturated and monounsaturated fatty acids, and increased saturated fatty acids components of the soy oil.

\begin{tabular}{lccc}
\hline & Saturated & Monounsaturated & Polyunsaturated \\
\hline Palm oil & & & \\
Fresh & 42.87 & 48.94 & 8.18 \\
Once heated & 42.64 & 49.24 & 8.52 \\
Five times heated & 43.25 & 48.21 & 7.97 \\
Soy oil & & & \\
Fresh & 16.69 & 25.00 & 52.48 \\
Once heated & 17.14 & 26.10 & 51.78 \\
Five times heated & 18.10 & 24.21 & 41.72 \\
\hline
\end{tabular}

Table 1. The percentage of saturated, monounsaturated and polyunsaturated fatty acids in the fresh, once and five times heated palm and soy oils.

\subsection{Vitamin E content in the oils}

The vitamin E isoforms, namely $\alpha-, \gamma$ - and $\delta$-tocopherols, $\alpha-, \gamma$ - and $\delta$-tocotrienols content in the oils is tabulated in Table 2. In palm oil, only $\alpha$-tocopherol, $\alpha$-, $\gamma$ - and $\delta$-tocotrienols were present. Whilst in soy oil, only tocopherol isoforms $(\alpha, \gamma$ and $\delta)$ were detected but none of tocotrienols. Fresh palm oil had larger content of total vitamin E compared to fresh soy oil. Once and five times heated palm oils had significantly lower content of all vitamin E isoforms than the fresh palm oil. In five times heated palm oil, all the isoforms content were also significantly reduced compared once heated palm oil. For soy oil, once and five times heating decreased the $\alpha$-tocopherol content significantly compared to the fresh oil. The contents of $\gamma$ - and $\delta$-tocopherols were only reduced significantly in five times heated soy oil compared to once heated and fresh soy oils.

The difference in vitamin E content relative to fresh palm oil is diagrammatically shown in Figure 2. The relative reductions in $\alpha$-tocopherol and all tocotrienol isoforms as well as total contents were greater in five times heated palm oil than once heated palm oil. The relative reduction was the least seen in the $\delta$-tocotrienol content. In once heated soy oil, a big relative 


\begin{tabular}{|c|c|c|c|c|c|c|c|}
\hline & \multicolumn{3}{|c|}{ Tocopherols (T) (ppm) } & \multicolumn{3}{|c|}{ Tocotrienols (T3) (ppm) } & \multirow{2}{*}{$\begin{array}{r}\text { Total } \\
\text { (ppm) }\end{array}$} \\
\hline & $\alpha \mathrm{T}$ & $\gamma \mathrm{T}$ & $\delta \mathrm{T}$ & $\alpha \mathrm{T} 3$ & $\gamma \mathrm{T} 3$ & $\delta \mathrm{T} 3$ & \\
\hline \multicolumn{8}{|l|}{ Palm oil } \\
\hline Fresh & $\begin{array}{l}178.3 \\
\pm 3.7\end{array}$ & ND & ND & $\begin{array}{r}188.5 \\
\pm 16.3\end{array}$ & $\begin{array}{r}260.8 \\
\pm 19.7\end{array}$ & $\begin{array}{r}69.8 \\
\pm 2.2\end{array}$ & 697.4 \\
\hline Once heated & $\begin{array}{c}79.0 \\
\pm 8.1^{*}\end{array}$ & ND & ND & $\begin{array}{c}80.2 \\
\pm 14.6^{*}\end{array}$ & $\begin{array}{c}193.2 \\
\pm 21.4^{*}\end{array}$ & $\begin{array}{c}59.8 \\
\pm 10.4^{*}\end{array}$ & 412.2 \\
\hline $\begin{array}{l}\text { Five times } \\
\text { heated }\end{array}$ & $\begin{aligned} & 3.3 \\
\pm & 3.3^{* \#}\end{aligned}$ & ND & ND & $\begin{aligned} & 3.8 \\
\pm & 3.8^{* \#}\end{aligned}$ & $\begin{array}{c}31.8 \\
\pm 20.8^{* \#}\end{array}$ & $\begin{array}{c}35.8 \\
\pm 11.6^{\text {*\# }}\end{array}$ & 74.7 \\
\hline \multicolumn{8}{|l|}{ Soy oil } \\
\hline Fresh & $\begin{array}{r}66.2 \\
\pm 1.4\end{array}$ & $\begin{array}{r}247.2 \\
\pm 15.0\end{array}$ & $\begin{array}{l}122.7 \\
\pm 0.7\end{array}$ & ND & ND & ND & 436.1 \\
\hline Once heated & $\begin{array}{c}25.3 \\
\pm 1.7^{*}\end{array}$ & $\begin{array}{l}254.7 \\
\pm 20.1\end{array}$ & $\begin{array}{l}127.7 \\
\pm 0.7\end{array}$ & ND & ND & ND & 407.7 \\
\hline $\begin{array}{l}\text { Five times } \\
\text { heated }\end{array}$ & $\begin{array}{c}11.5 \\
\pm 2.0^{*}\end{array}$ & $\begin{array}{c}97.8 \\
\pm 18.0^{* \#}\end{array}$ & $\begin{array}{c}80.5 \\
\pm 4.9^{* \#}\end{array}$ & ND & ND & ND & 189.8 \\
\hline
\end{tabular}

Table 2. Composition of tocopherols and tocotrienols ( $\mathrm{ppm}$ ) in the fresh, once and five times heated palm and soy oils. Values are mean \pm SEM $(n=6)$. *Significantly different from the fresh oils respectively $(\mathrm{P}<0.05)$, \#Significantly different from once heated oil respectively $(\mathrm{P}<0.05)$. ND, not detectable.

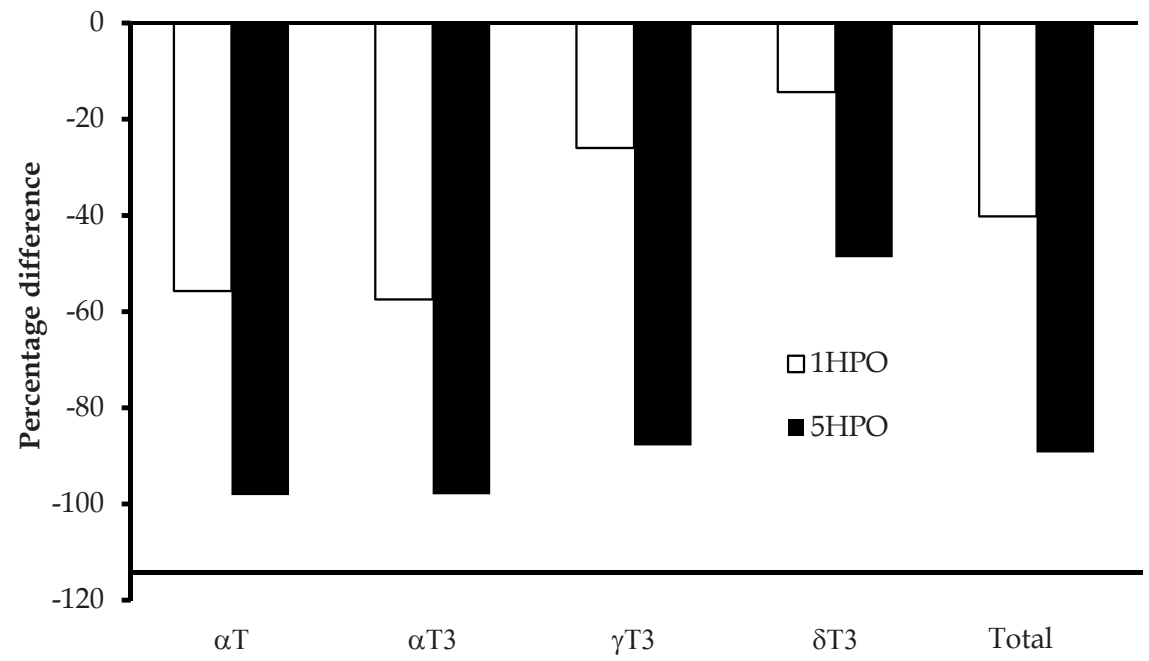

Figure 2. The percentage difference in $\alpha$-tocopherol ( $\alpha \mathrm{T}), \alpha$-tocotrienol ( $\alpha \mathrm{T} 3), \gamma$-tocotrienol $(\gamma \mathrm{T} 3)$ and $\delta$ tocotrienol ( $\delta \mathrm{T} 3)$ contents in heated palm oils (once and five times) in comparison to fresh palm oil. 
decrease was seen in $\alpha$-tocopherol content, whereas other isoforms content were not much affected. However, there was only a slight relative decrease in total vitamin E content. In five times heated soy oil, the relative reductions were seen in all tocopherol isoforms $(\alpha, \gamma$ and $\delta$ isoforms) (Figure 3). However, the least relative reduction was noted in the $\delta$ tocopherol content. It thus appeared that $\delta$-tocopherol and $\delta$-tocotrienol were more resistant to heat compared to $\alpha$ and $\gamma$ isoforms.

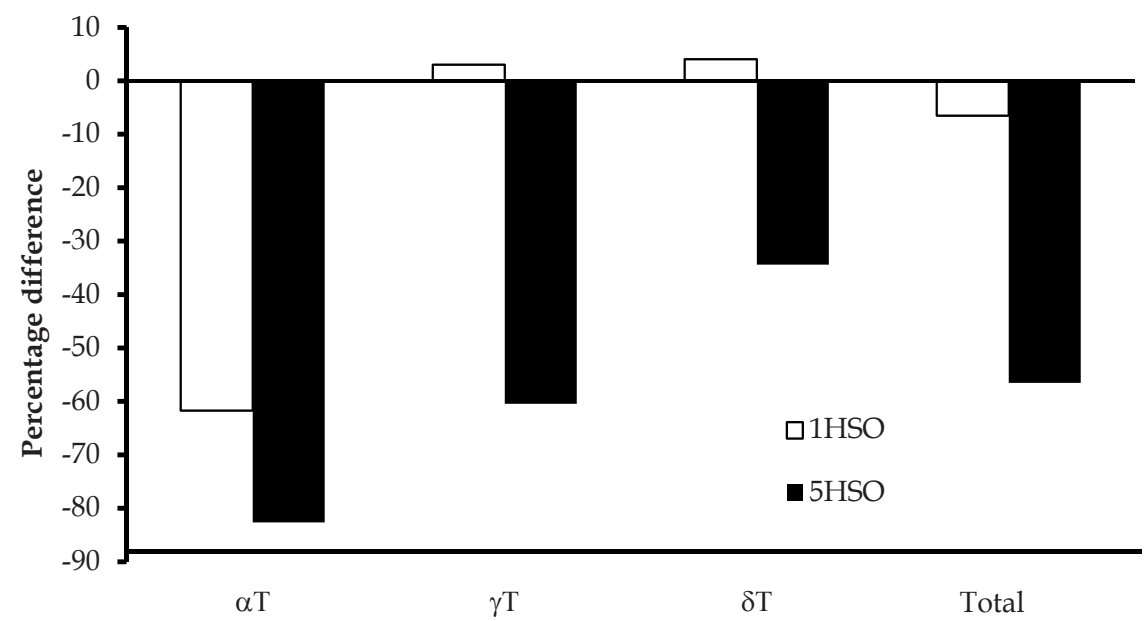

Figure 3. The percentage difference in $\alpha$-tocopherol $(\alpha \mathrm{T}), \gamma$-tocopherol $(\gamma \mathrm{T})$ and $\delta$-tocopherol $(\delta \mathrm{T})$ contents in heated soy oils (once and five times) in comparison to the fresh soy oil.

\subsection{Plasma lipid peroxidation in male rats}

Relative plasma lipid peroxidation, measured as TBARS was increased significantly in male rats that were given diet containing $15 \%$ once and five times heated palm or soy oil for 4 months compared to the control and fresh oils, respectively (Figure 4). The five times heated groups also had significantly higher TBARS content than the once heated groups, respectively. In the once and five times heated groups, the TBARS content was significantly elevated in the soy oil-fed group compared to the palm oil-fed group, respectively. Both fresh palm and soy oil groups had significantly lower relative plasma TBARS content than the control.

\subsection{Plasma lipid peroxidation in ovariectomized female rats}

Ovariectomized female rats that were fed once and five times heated palm and soy oils in addition to $2 \%$ cholesterol for four months had significantly elevated relative plasma TBARS compared to both groups that were given either control diet or fresh oil respectively. The rats that ingested five times heated oils had significantly higher plasma TBARS than the 


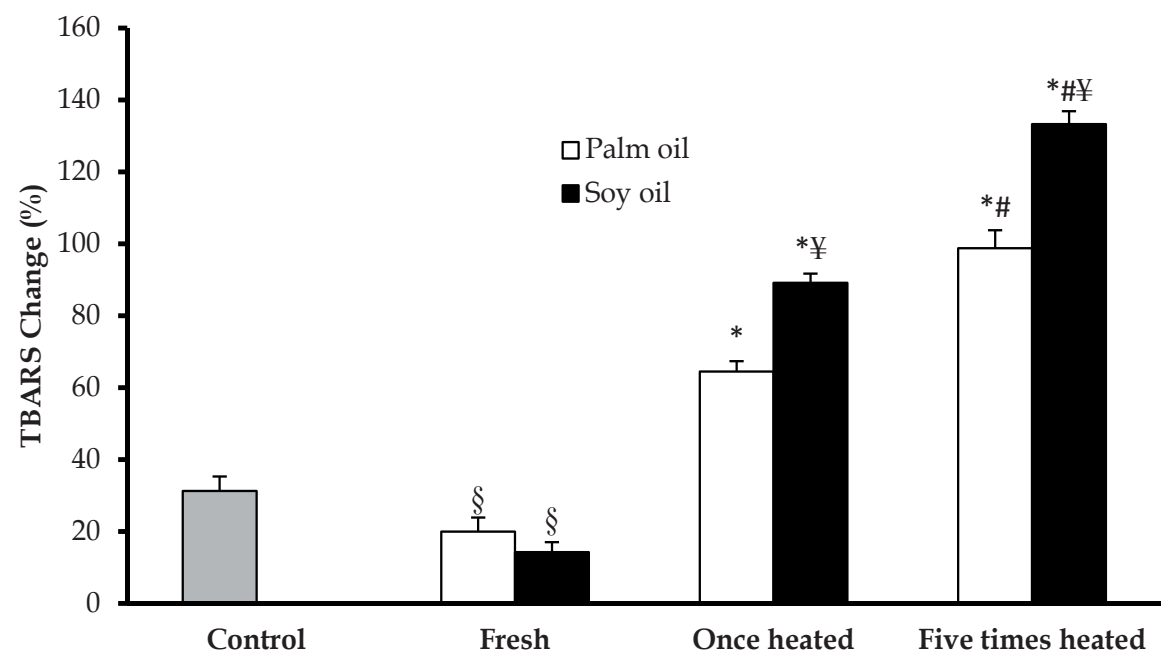

Figure 4. The change percentage of thiobarbituric acid reactive substance (TBARS), a lipid peroxidation product in male rats that were fed $15 \%$ once or five times heated (w/w) palm or soy oils for 4 months. Bars represent mean \pm SEM $(n=6)$. ${ }^{*}$ Significantly different from the control and fresh oil respectively $(\mathrm{P}<0.05)$. \#Significantly different from once heated soy oil $(\mathrm{P}<0.05)$. ¥Significantly different from the heated palm oil, respectively $(\mathrm{P}<0.05)$. §Significantly different from the control $(\mathrm{P}<0.05)$.

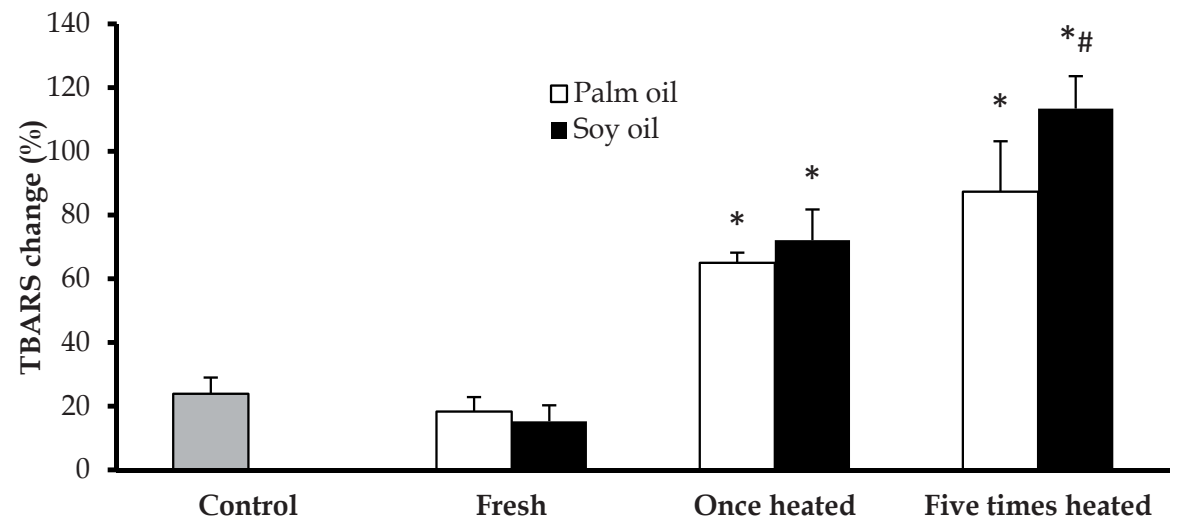

Figure 5. The percentage of change of lipid peroxidation product measured as thiobarbituric acid reactive substance (TBARS) in ovariectomised female rats that were fed $2 \%$ cholesterol together with $15 \%$ once or five times heated $(w / w)$ palm or soy oils for 4 months. Bars represent mean \pm SEM $(n=6)$. *Significantly different from the control and fresh oil respectively $(\mathrm{P}<0.05)$. \#Significantly different from once heated soy oil $(\mathrm{P}<0.05)$. 
once heated groups respectively. The plasma TBARS in palm oil-fed groups were similar to the soy oil-fed groups except in five times heated groups which the palm oil group had a lower plasma TBARS $(\mathrm{P}<0.05)$. The plasma TBARS of the fresh oil groups was not different from that of the control.

\section{Discussion}

Repeatedly heated cooking oil is often used interchangeably with thermoxidized or recycled cooking oil. Repeated use of this oil has become a common practice due to low level of awareness among the public about the bad effect of this practice [9]. Nowadays, the consumption of deep-fried food has gained popularity which may cause increased risk of obesity [24].

During frying, food is immersed in hot oil at a high temperature of $150{ }^{\circ} \mathrm{C}$ to $190{ }^{\circ} \mathrm{C}$. The heat and mass transfer of oil, food and air that occurs during deep frying produces the unique and desirable quality of fried foods [2]. It was shown in the present study that the peroxide values were increased with the increasing frequency of heating in both types of oil. Increased values indicate increased lipid peroxidation byproduct content, mainly the peroxides that were formed in the oil during heating process. The extent of oxidation in the oils was affected by the number of frying. Other than the peroxides, there are other oxidized components that are formed during oil heating such as oxidative dimers and oxidized triacylglycerols [25]. Only five times heated soy oil exceeded the upper limit of peroxide value set by the American Oil Chemists' Society (AOCS) that is $10 \mathrm{meq} / \mathrm{kg}$ oil [23]. However, if the Food Sanitation Law of Japan guideline (peroxide value $\leq 30 \mathrm{meq} / \mathrm{kg}$ oil) is used instead, all fresh and heated oils can be considered safe for human ingestion. However, a recent study done by Awney [26] has demonstrated that in male rats fed thermally oxidized soy oil with peroxide value of $14 \mathrm{meq} / \mathrm{kg}$, had significantly increased lipid peroxidation content in various organs such as liver, kidney, testes and brain. Chronic intake of repeatedly heated cooking could be harmful to health and increase risk of many diseases including hypertension [13] and cancer [10].

During heating at high temperature, several complex chemical reactions take place in the oil. It is dependent on the temperature, duration of heating, type of frying materials, type of oils, presence of antioxidant and prooxidant as well as the amount of oxygen [2,27]. Repeatedly heated oils at high temperature will undergo chemical conversion of fatty acid configuration from cis to trans isomer [28]. Diets containing trans fatty acid could be detrimental to cardiovascular health because it was reported that this fatty acid isomer could induce inflammation of the blood vessels and decrease its nitric oxide production [29-30]. The polymer and polar compounds content are also increased more than $37 \%$ and $47 \%$ respectively when the oil is used to fry [31]. The repeatedly heating would reduce the quality of cooking oil by darkening its color and changing the smell as well as the taste [1].

We found that the fresh and repeatedly heated soy oil had greater peroxide value than palm oil. The peroxide value is often used as an indicator for oxidative stability or the extent of degradation for fats and oils [32]. Therefore, greater values found in soy oil suggest that the 
soy oil were more susceptible to oxidative modification than palm oil. Vegetable oils rich in polyunsaturated fatty acid are more prone to oxidation compared to the oils which are rich in monounsaturated fatty acids [33]. Fats are usually oxidized by prooxidants or free radicals at the unsaturated bonds of the fatty acids, which are abundantly present in the polyunsaturated fatty acids such as linoleic (C18:2) and linolenic (C18:3) acids. The bigger the numbers of unsaturated bonds, the more prone the fatty acids are to oxidation. Intense heating of oils decreases unsaturation of the fatty acids [34].

The fresh soy oil contained about five times more polyunsaturated fatty acid compared to the palm oil. It seemed that five times heating had reduced about $10 \%$ of the polyunsaturated fatty acid content in the soy oil. The content of monounsaturated fatty acid in the fresh palm oil was higher than that of the fresh soy oil. Palm oil had a quite balanced ratio of saturated and unsaturated fatty acids, whereas more than $70 \%$ of soy oil fatty acid was unsaturated (polyunsaturated and monounsaturated). This unique fatty acid composition of palm oil renders its stability against oxidative insult. The fatty acid composition of heated soy oil [26] and palm oil [35] was similarly obtained in previous studies.

The examples of the monounsaturated are oleic (C18:1) and palmitoleic (C16:1), whereas palmitic (C16:0) and stearic (C18:0) are saturated fatty acids [26]. Soy oil majorly contains linoleic $(54 \%)$ and oleic $(23 \%)$ acids. It also contains linolenic $(8 \%)$, palmitic $(11 \%)$ and stearic $(4 \%)$ acids [26]. While palm oil has a bigger proportion of oleic $(46 \%)$ and palmitic acids $(36 \%)$, a smaller amount of linoleic $(12 \%)$ and linolenic $(<1 \%)$ acids, and similar proportion of stearic acid (4.5\%) compared to soy oil [36]. However in the present study, the individual fatty acid composition in the oil was not determined.

Most antioxidants are heat labile. Vitamin E is not an exception. When subjected to heat at high temperature, we found that all tocotrienol isoforms $(\alpha, \gamma$ and $\delta$ ) as well as $\alpha$-tocopherol in the palm oil were lost. It became more prominent when the oil was heated five times. The fresh palm oil contained almost 700 ppm of total vitamin E, but once and five times heating had further reduced it to barely 400 and 75 ppm, respectively. $\gamma$-Tocotrienol content was the highest in fresh and once heated palm oil, followed by $\alpha$-tocotrienol, $\alpha$-tocopherol and the least being the $\delta$-tocotrienol. Once heating caused almost $50 \%$ reduction in $\alpha$-tocopherol and $\alpha$-tocotrienol contents in palm oil. While the loss of other isoforms ( $\gamma$ - and $\delta$-tocotrienols) were at smaller percentages. In five times heated palm oil, the percentage loss of all vitamin E components were almost $100 \%$ except $\delta$-tocotrienol (almost $50 \%$ ), compared to the fresh palm oil. It seemed that amongst the tocotrienol isoforms, $\delta$-tocotrienol had the highest resistance to heat.

Different from palm oil, the soy oil exclusively contained $\alpha-, \gamma$ - and $\delta$-tocopherols. $\gamma$ Tocopherol was the largest constituent in the soy oil, followed by $\delta$-tocopherol and lastly $\alpha$-tocopherol. The total content of vitamin $\mathrm{E}$ in fresh soy oil was about $60 \%$ of that of fresh palm oil. Compared to tocopherols, tocotrienols are less widespread in plants [37]. Other than palm oil, tocotrienols are found abundantly in barley [38], rice bran [39], grape seed oil [40], rye, oat, maize and wheat germ [41]. Tocopherols on the other hand, are 
distributed at a wider range of food and vegetable oils such as soybean, corn, sunflower and cottonseed oils [40,42].

Once heating did not significantly affect $\gamma$ - and $\delta$-tocopherols contents in the soy oil, but the $\alpha$-tocopherol content was apparently reduced. However in five times heated, all tocopherol isoforms content were significantly decreased. When the percentage difference relative to the fresh soy oil calculated, the most prominent reduction was seen in $\alpha$-tocopherol content after once heating, followed by the $\gamma$-tocopherol and $\delta$-tocopherol contents. Quite a similar finding was reported by Rennick \& Warner [43] that the $\alpha$-tocopherol content of soy oil was significantly decreased when was heated for 5 hours and was further decreased after heated for 10 hours. The loss of the tocopherol content was accompanied by an increasing appearance of $\alpha$-tocopherolquinones.

From the findings obtained, it seemed that the loss of tocotrienol was more than the same isoform of tocopherol. The vitamin E chemical structure is consisted of a chromanol ring and a 15-carbon phytyl side chain. Tocotrienol differs from tocopherol by the presence of three unsaturated bonds in its phytyl chain [44]. The presence of unsaturations in the tocotrienol phytyl chain may explain the susceptibility of the compound to repeated heating. It was also noted that the $\alpha$ isoform of both tocopherol and tocotrienol was the mostly susceptible to oxidative loss in both palm and soy oils. The second sensitive isoform was the $\gamma$ isoform (both $\gamma$-tocopherol and tocotrienol), and the least sensitive being the $\delta$ isoform. The $\alpha$ isoform has three methylated groups, the $\gamma$ isoform has two while the $\delta$ isoform has only one methylated group on the chromanol ring [45]. However Miyagawa et al. [46] had reported that the decomposition rate of $\gamma$-tocopherol was the fastest, followed by $\delta$ - and $\alpha$-tocopherol when a mixture of soy and rapeseed oil was used to deep fry potato. The discrepancy could be due to the different type of oils used in their study. It can be postulated that the degree and position of the methylation on the chromanol ring also determine the susceptibility of the vitamer to oxidative loss in addition to the degree of saturation of the phytyl chain.

The higher vitamin E content in the palm oil than soy oil might contribute to lesser peroxide value in the former oil. Both tocopherols and tocotrienols possess antioxidant property, with the latter having greater antioxidant property [6]. Vitamin E could effectively protect the fatty acids in the oil from oxidation. During oil heating, the vitamin E is consumed by scavenging the lipid free radicals which are derived from the oxidation of unsaturated fatty acids in the oils. $\alpha$-Tocopherol addition to frying oil increased the stability and resistance of polyunsaturated fatty acid against oxidation [47]. Inclusion of antioxidants lemon seed extract and tert-butylhydroquinone was demonstrated to retard lipid oxidation and contribute to the $\alpha$-tocopherol retention in the soy oil heated at high temperatures for several hours [48].

Male rats that were fed heated oils had elevated plasma lipid peroxidation content. The elevation was more prominent with the five times heated oils. The increased peroxide value of the heated oils may be associated with the significant increase in plasma lipid peroxidation. Chronic ingestion of heated oil was shown to cause an elevation of blood pressure [49] and necrotic cardiac changes [50]. This would disrupt the endogenous 
antioxidant defense in our body in order to overcome the overwhelming of oxidative stress. Linoleyl, peroxy, and alkoxy radicals were reported to be produced in heated oils. These radicals act on the fatty acids of the oil producing oxidized products via hemolytic $\beta$-scission [25]. Dietaries fresh palm and soy oil were shown to attenuate oxidative stress and augment antioxidant enzymes activities in rat models [51-53]. Their findings are in agreement with the present study where a significant reduction in plasma lipid peroxidation was observed in the fresh oil-fed male rats. This positive effect was attributed to the rich antioxidant content of the oils.

Heating diminished the vitamin E content and rendered the oils to lose their beneficial effects. Chronic ingestion of heated soy oil diet was shown to induce the increase in hepatic lipid peroxidation in rats [54]. They also observed a reduction in serum and hepatic vitamin E content in rats that were fed heated oil containing diet. An evidence of hepatic damage was also reported with a significant elevation of aspartate and alanine transaminases, the marker enzymes for liver function in rats that were given combination of heated soy and rapeseed oils [55]. The administration of dietary heated soy oil affected the activities of antioxidant enzymes in various rat organs. It increased superoxide dismutase in the liver and brain, while increment in glutathione reductase was seen in the liver and kidneys [26]. Heated palm oil also increased catalase, glutathione peroxidase and glutathione Stransferase in the rat liver [35]. It shows dietary heated oil contained prooxidant substances that would evoke the body primary defenses.

Plasma lipid peroxidation was increased significantly in the rats that were given heated soy oil (once and five times heated) when compared to the heated palm oil-fed groups. This finding was suggestive of the better effect of the palm oil in terms of oxidative stability when exposed to extreme heat. High composition of saturated fats in palm oil confers it to withstand thermal oxidative changes, in addition to its rich content of tocotrienols. The better effect of heated palm oil compared to heated soy oil was reported elsewhere [56].

Ovariectomized female rats were often used as an experimental postmenopausal model. Ovariectomy results in an estrogen deficiency state. The estrogen provides protection to the body against oxidative stress [16]. In the present study, dietaries once heated and five times heated palm and soy oil for four months had significantly increased the plasma lipid peroxidation in ovariectomized female rats. The result is in agreement with other studies which also reported that in ovariectomized-induced estrogen deficiency, an increase in oxidative stress accompanied by a reduction in antioxidant status was seen [57-58]. A study by Sánchez-Rodríguez [59] had recently found that menopause could be one of the main risk factors for oxidative stress. Therefore, this finding suggests that chronic ingestion of repeatedly heated vegetable oils is detrimental to health and could further aggravate the increase in oxidative stress in postmenopausal women. Shuid et al. [56] also had demonstrated that fresh and once heated palm and soy oil diets for six months reduced the risk of osteoporosis in ovariectomized rats, a positive effect that was not seen in rats that were fed five times heated oils. 
The patterns of plasma lipid peroxidation increase in both male and ovariectomized female rats were somewhat similar. However, the plasma lipid peroxidation of the fresh oil-fed groups in the ovariectomized female rats that were similar to the control group, different from the one observed in the male rats. The addition of dietary $2 \%$ cholesterol and the ovariectomy status of the female rats made them more susceptible to oxidative insult. This may explain why there was no significant reduction in plasma TBARS seen in the female rats fed fresh oils compared to the control. The plasma lipid peroxidation was significantly elevated in the five times heated soy oil group compared to the same heating frequency of palm oil. The difference was also attributed to the higher component of polyunsaturated fatty acids present in the soy oil, which are prone to oxidation.

\section{Conclusion}

Our findings suggest that it is recommended not to heat cooking oil more than once in view of its possible deleterious effect on health. The use of palm oil possibly has better effect on health due to its stability against oxidative insult.

\section{Author details}

Kamsiah Jaarin and Yusof Kamisah

Department of Pharmacology, Faculty of Medicine, Universiti Kebangsaan Malaysia, Malaysia

\section{Acknowledgement}

The study was funded by grants from Universiti Kebangsaan Malaysia (UKM-GUP-SK-0821-299) and Malaysian Ministry of Science, Technology and Innovations (IRPA 06-02-020050-EA242). The authors also would like to thank Prof. Dr Jumat Salimon, Ms Xin-Fang Leong and Mr. Chun-Yi Ng for their technical help as well as Ms Jurika Sharaton Abdul Wahed for editorial assistance.

\section{References}

[1] Rani AKS, Reddy SY, Chetana R (2010) Quality changes in trans and trans free fats/oils and products during frying. Eur. Food Res. Technol. 230(6): 803-811.

[2] Choe E, Min DB (2007) Chemistry of deep-fat frying oils. J. Food Sci. 72(5):R77-R86.

[3] Choe, E. \& Min, D. B (2006) Chemistry and reactions of reactive oxygen species in foods. Crit. Rev. Food Sci. Nutr. 46(1): 1-22.

[4] Kamisah Y, Adam A, Wan Ngah WZ, Gapor MT, Azizah O, Marzuki A (2005) Chronic intake of red palm olein and palm olein produce beneficial effects on plasma lipid profile in rats. Pakistan J. Nutr. 4(2): 89-96

[5] Clemente TE, Cahoon EB (2009) Soybean oil: genetic approaches for modification of functionality and total content. Plant Physiol. 151(3): 1030-1040.

[6] Bardhan J, Chakraborty R, Raychaudhuri U (2011). The $21^{\text {st }}$ century form of vitamin E Tocotrienol. Curr. Pharm. Des. 17(21): 2196-2205. 
[7] Edem DO (2002) Palm oil: biochemical, physiological, nutritional, hematological, and toxicological aspects: a review. Plant Foods Hum. Nutr. 57(3-4): 319-341.

[8] Azman, SM Shahrul, XS Chan, AP Noorhazliza, M Khairunnisak, MF Nur Azlina, HMS Qodriyah, Y Kamisah, K Jaarin (2012) Level of knowledge, attitude and practice of night market food outlet operators in Kuala Lumpur regarding the usage of repeatedly heated cooking oil. Med. J. Malays. 67(1): 97-107.

[9] Abdullah A, Shahrul S, Chan XS, Noorhazliza AP, Khairunnisak M, Qodriyah HMS, Kamisah Y, Nur Azlina MF, Kamsiah J (2010) Level of awareness amongst the general public regarding usage of repeatedly heated cooking oil in Kuala Lumpur, Malaysia. Inter. Med. J. 17(4): 310-311.

[10] Srivastava S, Singh M, George J, Bhui K, Murari Saxena A, Shukla Y (2010) Genotoxic and carcinogenic risks associated with the dietary consumption of repeatedly heated coconut oil. Br. J. Nutr. 104(9): 1343-1352.

[11] Obembe AO, Owu DU, Okwari OO, Antai AB, Osim EE (2011) Intestinal Fluid and Glucose Transport in Wistar Rats following Chronic Consumption of Fresh or Oxidised Palm Oil Diet. ISRN Gastroenterol. 2011: 972838.

[12] Latha P, Chaitanya D, Rukkumani R (2010) Protective effect of Phyllanthus niruri on alcohol and heated sunflower oil induced hyperlipidemia in Wistar rats. Toxicol Mech. Methods. 20(8): 498-503.

[13] Soriguer F, Rojo-Martínez G, Dobarganes MC, García Almeida JM, Esteva I, Beltrán M, Ruiz De Adana MS, Tinahones F, Gómez-Zumaquero JM, García-Fuentes E, GonzálezRomero S (2003) Hypertension is related to the degradation of dietary frying oils. Am. J. Clin. Nutr. 78(6): 1092-1097.

[14] Rossouw JE (2002) Hormones, genetic factors and gender differences in cardiovascular disease. Cardiovasc. Res. 53: 550-557.

[15] Lu H, Meléndez GC, Levick SP, Janicki JS (2012) Prevention of adverse cardiac remodeling to volume overload in female rats is the result of an estrogen-altered mast cell phenotype. Am. J. Physiol. Heart Circ. Physiol. 302(3): H811-H817.

[16] Abbas AM, Elsamanoudy AZ (2011) Effects of 17 $\beta$-estradiol and antioxidant administration on oxidative stress and insulin resistance in ovariectomized rats. Can. J. Physiol. Pharmacol. 89(7): 497-504.

[17] Shuid AN, Mohamad S, Muhammad N, Fadzilah FM, Mokhtar SA, Mohamed N, Soelaiman IN (2011) Effects of $\alpha$-tocopherol on the early phase of osteoporotic fracture healing. J. Orthop. Res. 29(11): 1732-1738.

[18] Mvondo MA, Njamen D, Fomum ST, Wandji J, Vollmer G (2011) A postmenopause-like model of ovariectomized Wistar rats to identify active principles of Erythrina lysistemon (Fabaceae). Fitoterapia. 82(7): 939-949.

[19] Owu DU, Osim EE, Ebong PE (1998) Serum liver enzymes profile of Wistar rats following chronic consumption of fresh or oxidized palm oil diets. Acta Trop. 69(1): 6573.

[20] AOCS (2003) Official methods and recommended practices of the American Oil Chemists' Society. 4th ed. AOCS Press, Champaign, Illinois. 
[21] Ledwozyw A, Michalak J, Stepian A, Kadziolka A (1986) A relationship between plasma triglycerides, cholesterol, total lipids and lipid peroxidation products during human atherosclerosis. Clin. Chim. Acta. 155: 275-285.

[22] Lowry OH, Rosebrough NJ, Farr AL, Randall RJ (1951) Protein measurement with Folin Phenol reagent. J. Biol. Chem. 193: 265-275.

[23] Matthaus B (2006) Utilization of high-oleic rapeseed oil for deep-fat frying of French fries compared to other commonly used edible oils. Eur. J. Lipid Sci. Tech. 108(3): 200211.

[24] Sayon-Orea C, Bes-Rastrollo M, Basterra-Gortari FJ, Beunza JJ, Guallar-Castillon P, de la Fuente-Arrillaga C, Martinez-Gonzalez MA (2012) Consumption of fried foods and weight gain in a Mediterranean cohort: The SUN project. Nutr. Metab. Cardiovasc. Dis. (in press)

[25] Picariello G, Paduano A, Sacchi R, Addeo F (2009) Maldi-tof mass spectrometry profiling of polar and nonpolar fractions in heated vegetable oils. J. Agric. Food Chem. 57(12): 5391-5400.

[26] Awney HA (2011) The effects of Bifidobacteria on the lipid profile and oxidative stress biomarkers of male rats fed thermally oxidized soybean oil. Biomarkers. 16(5): 445-452.

[27] Leskova E, Kubikova J, Kovacikova E, Kosicka M, Pobruska J, Holcikova K (2006) Vitamin losses: Retention during heat treatment and continual changes expressed by mathematical models. J. Food Comp. Anal. 19: 252-276.

[28] Velasco J, Marmesat S, Bordeaux O, Márquez-Ruiz G, Dobarganes C (2004) Formation and evolution of monoepoxy fatty acids in thermoxidized olive and sunflower oils and quantitation in used frying oils from restaurants and fried-food outlets. J. Agr. Food Chem. 52(14): 4438-4443.

[29] Iwata NG, Pham M, Rizzo NO, Cheng AM, Maloney E, Kim F (2011) Trans fatty acids induce vascular inflammation and reduce vascular nitric oxide production in endothelial cells. PLoS One. 6(12): e29600.

[30] Bryk D, Zapolska-Downar D, Malecki M, Hajdukiewicz K, Sitkiewicz D (2011) Trans fatty acids induce a proinflammatory response in endothelial cells through ROSdependent nuclear factor- $\kappa B$ activation. J. Physiol. Pharmacol. 62(2): 229-238.

[31] Saka S, Aouacheri W, Abdennour C (2002) The capacity of glutathione reductase in cell protection from the toxic effect of heated oils. Biochimie 84(7): 661-665.

[32] Karoui IJ, Dhifi W, Jemia MB, Marzouk B (2011) Thermal stability of corn oil flavoured with Thymus capitatus under heating and deep-frying conditions. J. Sci. Food Agr. 91(5): 927-933.

[33] Kochhar SP, Henry CJ (2009) Oxidative stability and shelf-life evaluation of selected culinary oils. Inter. J. Food Sci. Nutr. 60(7 Suppl): 289-296.

[34] Moya Moreno MC, Mendoza Olivares D, Amézquita López FJ, Gimeno Adelantado JV, Bosch Reig F. Analytical evaluation of polyunsaturated fatty acids degradation during thermal oxidation of edible oils by Fourier transform infrared spectroscopy. Talanta. 1999 Sep 13;50(2):269-75. 
[35] Purushothama S, Ramachandran HD, Narasimhamurthy K, Raina PL (2003) Long-term feeding effects of heated and fried oils on hepatic antioxidant enzymes, absorption and excretion of fat in rats. Mol. Cell Biochem. 247(1-2): 95-99.

[36] Vara Prasad SS, Jeya Kumar SS, Kumar PU, Qadri SS, Vajreswari A (2010) Dietary fatty acid composition alters 11 $\beta$-hydroxysteroid dehydrogenase type 1 gene expression in rat retroperitoneal white adipose tissue. Lipids Health Dis. 9: 111.

[37] Horvath G, Wessjohann L, Bigirimana J, Jansen M, Guisez Y, Caubergs R, Horemans N (2006) Differential distribution of tocopherols and tocotrienols in photosynthetic and non-photosynthetic tissues. Phytochemistry. 67: 1185-1195.

[38] Shen Y, Lebold K, Lansky EP, Traber MG, Nevo E (2011) 'Tocol-omic' diversity in wild barley, short communication. Chem. Biodivers. 8(12): 2322-2330.

[39] Huang SH, Ng LT (2011) Quantification of tocopherols, tocotrienols, and $\gamma$-oryzanol contents and their distribution in some commercial rice varieties in Taiwan. J. Agric. Food Chem. 59(20): 11150-11159.

[40] Hassanein MM, Abedel-Razek AG (2009) Chromatographic quantitation of some bioactive minor components in oils of wheat germ and grape seeds produced as byproducts. J. Oleo Sci. 58(5): 227-233.

[41] Milagros Delgado-Zamarreño M, Bustamante-Rangel M, Sierra-Manzano S, VerdugoJara M, Carabias-Martínez R (2009) Simultaneous extraction of tocotrienols and tocopherols from cereals using pressurized liquid extraction prior to LC determination. J. Sep. Sci. 32(9): 1430-1436.

[42] Traber MG (2007) Vitamin E regulatory mechanisms. Annu. Rev. Nutr. 27: 347-362.

[43] Rennick KA, Warner K (2006) Effect of elevated temperature on development of tocopherolquinones in oils. J. Agric. Food Chem. 54(6): 2188-2192.

[44] Sen CK, Rink C, Khanna S (2010) Palm oil-derived natural vitamin E alpha-tocotrienol in brain health and disease. J. Am. Coll. Nutr. 29(3 Suppl): 314S-323S.

[45] Aggarwal BB, Sundaram C, Prasad S, Kannappan R (2010) Tocotrienols, the vitamin E of the 21st century: its potential against cancer and other chronic diseases. Biochem. Pharmacol. 80(11): 1613-1631.

[46] Miyagawa K, Hirai K, Takezoe R (1991) Tocopherol and fluorescence levels in deepfrying oil and their measurement for oil assessment. J. Am. Oil Chem. Soc. 68: 163166.

[47] Quiles JL, Ramírez-Tortosa MC, Ibáñez S, Alfonso González J, Duthie GG, Huertas JR, Mataix J (1999) Vitamin E supplementation increases the stability and the in vivo antioxidant capacity of refined olive oil. Free Radic. Res. 31 Suppl: S129-S135.

[48] Luzia DM, Jorge N (2009) Oxidative stability and alpha-tocopherol retention in soybean oil with lemon seed extract (Citrus limon) under thermoxidation. Nat. Prod. Commun. 4(11): 1553-1556.

[49] Leong X, Najib MNM, Das S, Mustafa MR, Jaarin K (2009) Intake of repeatedly heated palm oil causes elevation in blood pressure with impaired vasorelaxation in rats. Tohoku J. Exp. Med. 219: 71-78. 
[50] Leong XF, Aishah A, Aini UN, Das S, Jaarin K (2008) Heated palm oil causes rise in blood pressure and cardiac changes in heart muscle in experimental rats. Arch. Med. Res. 39: 567-572.

[51] Bayorh MA, Abukhalaf IK, Ganafa AA (2005) Effect of palm oil on blood pressure, endothelial function and oxidative stress. Asia Pac. J. Clin. Nutr. 14(4): 325-339.

[52] Narang D, Sood S, Thomas M, Dinda AK, Maulik SK (2005) Dietary palm olein oil augments cardiac antioxidant enzymes and protects against isoproterenol-induced myocardial necrosis in rats. J. Pharm. Pharmacol. 57(11): 1445-1451.

[53] Hassan HA, Abdel-Wahhab MA (2012) Effect of soybean oil on atherogenic metabolic risks associated with estrogen deficiency in ovariectomized rats : Dietary soybean oil modulate atherogenic risks in overiectomized rats. J. Physiol. Biochem. (in press).

[54] Corcos-Benedetti P, Di Felice M, Gentili V, Tagliamonte B, Tomassi G (1990) Influence of dietary thermally oxidized soybean oil on the oxidative status of rats of different ages. Ann. Nutr. Metab. 34(4): 221-231.

[55] Totani N, Burenjargal M, Yawata M, Ojiri Y (2008) Chemical properties and cytotoxicity of thermally oxidized oil. J. Oleo. Sci. 57(3): 153-160.

[56] Shuid AN, Chuan LH, Mohamed N, Jaarin K, Fong YS, Soelaiman IN (2007) Recycled palm oil is better than soy oil in maintaining bone properties in a menopausal syndrome model of ovariectomized rat. Asia Pac J Clin Nutr. 16(3): 393-402.

[57] Huang YH, Zhang QH (2010) Genistein reduced the neural apoptosis in the brain of ovariectomised rats by modulating mitochondrial oxidative stress. Br. J. Nutr. 104(9): 1297-1303.

[58] Topçuoglu A, Uzun H, Balci H, Karakus M, Coban I, Altug T, Aydin S, Topçuoglu D, Cakatay U (2009) Effects of estrogens on oxidative protein damage in plasma and tissues in ovariectomised rats. Clin. Invest. Med. 32(2): E133-143.

[59] Sánchez-Rodríguez MA, Zacarías-Flores M, Arronte-Rosales A, Correa-Muñoz E, Mendoza-Núñez VM (2012) Menopause as risk factor for oxidative stress. Menopause. 19(3): 361-367. 